\title{
Network-centric concept of tourist and recreational systems management: municipal aspect
}

\author{
V.A. Minaev ${ }^{1}$, E.A. Tsyshchuk ${ }^{2}$, G.Yu. Tsyshchuk ${ }^{3}$ \\ m1va@yandex.ru|evgenytsyshchuk@gmail.com|gtsyshchuk@list.ru \\ ${ }^{1}$ Bauman State Technical University, Moscow, Russia \\ ${ }^{2}$ ANO "Scientific Research Center for Physical and Technical Informatics", Nizhny Novgorod, Russia \\ ${ }^{3}$ Business School of Synergy University, Moscow, Russia
}

\begin{abstract}
The article discusses the theoretical and applied aspects of a new approach to the management of tourist and recreational systems based on a network-centric model. The model is based on the application of a network structure of information exchanges between tourist enterprises, consumers of tourist services and marketing organizations. In this network structure, clusters or aggregations of objects consisting of homogeneous small and medium-sized tourist enterprises are distinguished. The principle of self-synchronization in the network-centric construction of management in tourist and recreational systems is considered. The concept of "tourist and recreational attractor" is introduced. The strategy of "borrowing" in the application of mechanisms for the diffusion of innovations and advanced tourist and recreational technologies in the tourism industry of Russian regions is justified. A multi-network scheme of innovative development of the tourist and recreational sphere, including the educational segment, is proposed. The tourist and recreational system is considered at the municipal level. A multi-network scheme of innovative development of the tourist and recreational sphere, including the educational segment, is proposed. Approbation of the research results was carried out within the framework of tourist and recreational design of the Moscow and Tver regions municipalities. It is concluded that the network-centric concept, being innovative, has a high applied value and allows solving existing problems in their interrelation, providing competitive indicators (the volume of tourism, employment of supporting personnel, the size of investments). The results obtained in the study can be successfully replicated at the regional level of tourism and recreation management.
\end{abstract}

Keywords: tourism and recreation system, management, network-centric model, network technologies, self-synchronization, attractor, "borrowing" strategy, educational segment.

\section{Introduction}

In recent years the scientific community has been actively discussing issues related to the development and practical implementation of new scientific and methodological approaches to the construction of effective tourist and recreational systems (TRS) of various levels and scales.

Analysis such works introduced two key features inherent in them:

1) Insufficiently comprehensive analysis of the factor complex based mainly on the study of the internal environment and industry characteristics without taking into account other spheres of society and human activity.

2) Lack of consistency in the management of TRS as an integral unity of elements that are interconnected with each other.

Consequently the main decisions don't fully reflect the changes taking place in society, belated and ineffective in their content. At the same time cannot be ignored that over the past two decades a qualitatively new rapidly developing information environment has formed in the world connecting more than one and a half billion computers. Mobile communication networks connect more than four billion subscribers moreover a significant part of which are consumers of tourist and recreational services. In this situation the effectiveness of the functioning of any TRS objectively becomes directly dependent on its information and technological potential. And the "center of gravity" of management applications actively shifts from loosely coupled local computer systems to global information networks integrated into the network-centric space.

In this regard it is extremely important from the scientific and practical points of view to substantiate the concept of management of tourist and recreational systems based on network-centric approaches.

The theory and applied science of network-centric control of complex systems has been actively developing for the last years as a new effective paradigm for the survival of modern socio-economic structures in the context of the large-scale use of info communication technologies and the globalization of all significant processes of human existence $[1,2]$.

The network-centric paradigm is based on the network principle of building a particular system which makes it possible to provide maximum opportunities for obtaining information about the parameters of its own functioning and the state of the external environment, access to the named information, its processing, storage, distribution and feedback $[3,4]$.

For solving research problems TRS is considered by authors as a tourist and recreational complex (TRC) of a municipal formation, the key subsystems of which are: tourist and recreational resources, tourist and supporting infrastructure, tourists and recreants as consumers of tourist products and services, economic entities (participants in the tourist market, engaged in the formation and sale of the aggregate tourist product) [5].

It is no accident the municipal level is of the greatest interest. On the one hand, it is the least abundant resource in our country due to the peculiarities of inter-budgetary relations. On the other hand - at this level that the conditions for the implementation of tourist and recreational activities are formed, including the formation of the tourist product itself. Moreover, tourist and recreational activities at the municipal level have network-centric character.

Practice shows that the highest efficiency in the development of tourism today is achieved by precisely those regions in whose territory design and management 
decisions are initiated by municipal authorities and the local community. Conditions arise for the development of networking and cooperation, where tourism develops "locally" and the initiative comes "from below". Eventually successful projects are being implemented, positively perceived by entrepreneurs and investors. Thus, today the municipal level of government becomes the basis not only for the development of regional, but also for all-Russian tourism in general.

The results of the research carried out by the authors in Central Russia (Moscow and Tver regions) made it possible to study and systematize the problems of managing tourist and recreational complexes and highlight the key ones inherent in the overwhelming number of municipalities.

\section{The problem of unbalancing strategic decisions. Lack of networking between authorities}

Studies show municipalities have significantly increased their activities in the field of tourism over the past five years. The main reason for this activity is the search for new opportunities for diversification and growth of the local economy as well as for solving urgent social issues. Moreover, this is equally relevant both for urban settlements, which form the bulk of the gross municipal product, and for rural settlements, which today find themselves in a rather difficult situation.

The revitalization of the Moscow region is characterized by increased inter-municipal competition and a low level of inter-municipal cooperation in the development and promotion of tourism products. Usually as a strategic goal of tourism development most heads of the Moscow region see the concentration of consumer activity on their territory. Taking into account the existing budgetary system and the system of administrativeterritorial management the position of the heads of the Moscow region (to achieve success within their administrative boundaries and to concentrate consumer activity in themselves) can be partly accepted. But achieving such goal is associated with high costs and the result is not always obvious. Moreover, it is short-term and volatile.

This contradiction is manifested in the imbalance of strategic design decisions in the field of tourism at the regional and municipal levels and systemic errors in the development of infrastructure. Unfortunately, we don't aware of any of the territorial planning schemes clearly presenting the arguments regarding the integrated development of tourism and supporting infrastructure based on the existing tourism and recreation resources and the possibilities of inter-municipal and interregional interaction. There are no comprehensive and coordinated solutions for the development of intermodal tourist routes and the creation of "tourist hubs". Often budget investments aimed at the development of engineering and road transport infrastructure turn out to be ineffective. Business is hesitant to invest in tourism considering alternative options for investing their capital.

In the context of the problem under consideration the issue of interaction between regional and municipal authorities in the field of tourist and recreational development of territories remains unresolved. Often the tourism development strategies and programs approved by the local authorities of the Moscow region don't agree with the strategic planning documents at the regional level.

Uneven distribution of tourist and recreational potential. The study results show that the uneven distribution of tourist and recreational potential is a fairly common phenomenon, characteristic of both socioeconomically developed territories, and depressive, experiencing serious difficulties in attracting investment and human resources [5]. As a rule, tourist resources and infrastructure are very unevenly distributed among the settlements of the Moscow region, gravitating towards the regional center. An example characterizing such unevenness in relation to the settlements of the Klinsky district is shown in Fig. 1.

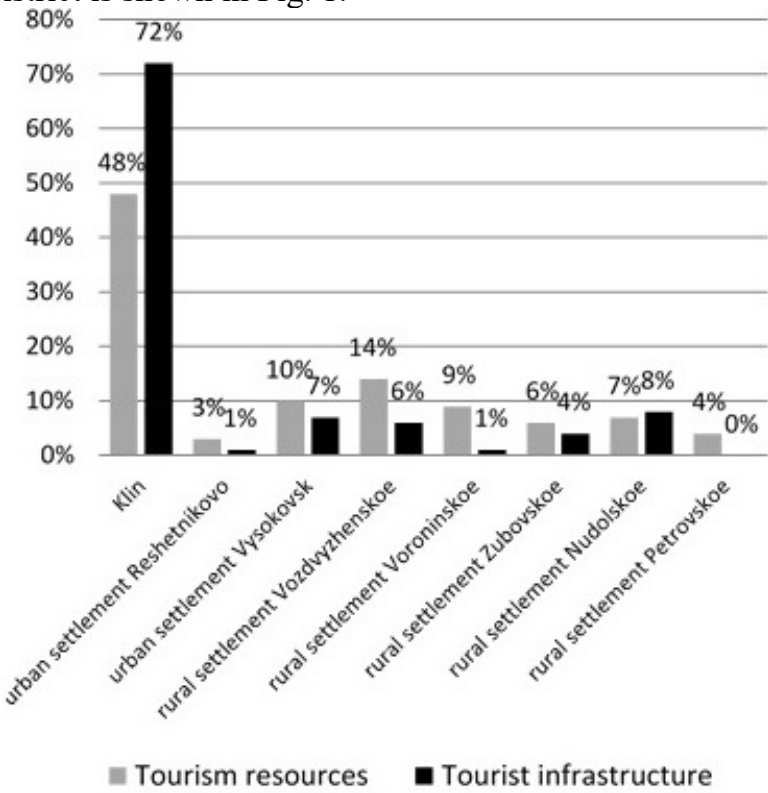

Fig. 1. Integral potential distribution of the of tourist resources and tourist infrastructure in the settlements of the Klinsky district of the Moscow region

\section{The problem of strategic selection arises}

First, to concentrate on the development of the most developed settlements in terms of tourism and get a quick but unstable effect. Second, to develop the territory systematically by strengthening weak territorial formations at the expense of stronger ones in terms of tourism. In the short term the second option will not be as effective as the first and will require significant administrative, management efforts and financial resources. But it provides a sustainable effect in the long term.

\section{The problem of finding and reconciling goals for the development of tourism}

Depending on the motivational attitudes of the heads of the authorities the resource potential the standard of living of the population and the conditions for conducting economic activities, various municipalities form different priorities in relation to tourism.

Our studies show that for industrialized or recreational areas, as well as small historical cities, the main priority in most cases is economic. For depressed territories mainly 
with agricultural specialization priority is social. Obviously such a division is conditional since in the long term the results of social projects can be transformed into economic ones.

\section{The problem of building a tourism management system}

Studies show that the issues of building a tourism management system at the local level are solved in different ways. Authorized bodies, as a rule, are created on the basis of subordinate municipal organizations or structural divisions of the administration. Where there is no mandate for tourism development, there are coordination or community councils. But in most cases these entities are bodies that do not make important decisions. It should be noted, that regardless of its structure, so far none of the tourism development management systems we have considered has proven to be effective. Three main reasons for this can be distinguished. First of all, the priorities for tourism at the local level are not clearly defined. The second, the issues of organizing interdepartmental interaction between government bodies and professional participants in the tourism market have not been resolved. The third, such an important institution as the tourist community has not been formed. The organization of network interaction and the development of industry cooperation in the formation and promotion of tourism products today is a "problem area" for most territories.

Therefore goal of this study is to substantiate the network-centric concept of management of tourist and recreational systems in general and to highlight the features inherent in systems of the municipal level.

\section{Materials and method}

\section{Network-centric technologies in the tourism sector}

A systematic and coordinated approach to the application of network-centric technologies, principles and methods in the tourism industry allows us to speak about its holistic purposeful development.

This is precisely that authors said in papers [6, 7], in which they come to the following conclusions:

- the interconnection and mutual development of tourism processes and information technologies determine in the tourism market a consistent change in structures, players and tourism products in order to adapt to the rapidly changing consumer behavior of the latter;

- the tourism sector is forced to rely on more flexible technological infrastructures that facilitate the development of business networks at the local level of destinations;

- these networks can be considered as "clusters" or aggregations of structures, consisting mainly of small and medium-sized tourism enterprises, which using new web technologies and modern mechanisms of market interaction, help each other (the "B2B" principle), providing the customer with a "complete package" of tourist's products and services;
- in the context of growing competition in the ecommerce market for tourism products and services in the absence of a destination management system (DMS) that enhances interaction between suppliers, customers and marketing organizations, destinations will not be able to maintain their tourist attractiveness;

- destinations need to differentiate their products and develop public-private partnerships in the tourism market.

It follows that the network-centric management of TRS involves the creation of a geographically distributed network of developed information communication nodes. The main characteristics of this network are [8]: a highly efficient "information grid" that provides access to all necessary information about the destination, an advanced tourism resource management system for the destination, an integrated "touch surface" connected to a single network with a system of "destination agents" and a management system her.

Thus, the TRS itself begins to act as the center of management and coordination in the network-centric paradigm of organizing the management of tourist and recreational resources, sharply reducing the role of intermediaries (tourist operators and traditional agents) to a greater extent reflecting the interests of the operators.

\section{Synergistic effects and attractors}

In a scientific and practical sense such a structure of the TRS organization will allow the transition to its more efficient and operational form of management and selfsynchronization.

At the same time the indicator of management efficiency implies two interrelated aspects:

- TRS achieves information superiority, which is understood as a more analytical understanding of the situation in a highly competitive field of activity;

- in technological terms such superiority presupposes the introduction of new management systems, computer analysis, assessment and forecasting based on modern mathematical models.

The principle of self-synchronization in the networkcentric structure of management in TRS implies the ability of the tourist and recreational structure to self-organize "from below", and not to reform in the administrative order. The named principle is embodied in a developed global computer environment with network-centric control of high structural complexity $[9,10]$.

A lot of studies $[11,12]$ have been written about selforganization as the main subject of science called "synergetic", in which an attempt is made to generalize the main laws of complex systems, to apply them to analyze social development. To apply its principles in the management of the tourism industry it is necessary to know the laws of stochastic processes, the theory of nonlinear systems, to operate with the concepts of phase space, an attractor as a goal, a stable state in the process of evolution of a particular system.

Without going into the details of the apparatus of synergetic within the framework of its terminology we will mean by a "tourist and recreational attractor" a steady state of TRS in a particular country which tends to attract to itself a set of trajectories of the system sufficient for its 
effective existence and development, determined by the possibilities and preferences of travelers, behaving like a set of active elements of the network-centric system [13]. In [14], attractors mean some "funnels" that roll up, pull in many trajectories, and predetermine the evolution of the system in areas even remote from the immediate "cone" of such a "funnel".

Attractors have such an important feature that if an object, being in it, leaves this state, then after some time it will return to the attractor again, exhibiting the property of asymptotic stability. What is the unknown property of tourists to strive for their own, once tested and successfully accepted attractor-destination?

Of course, the general theory of attractors as applied to the tourist and recreational sphere should be translated into the language of specific methods, techniques and recommendations [15]. The idea is debut taking into account the fact that the process of TRS development is increasingly streamlined in the direction of their dominant network-centric role. And the development of this idea for the named sphere is associated with the concepts of fluctuation, chaos, bifurcation, dissipation, diffusion of innovations, that is, a new conceptual apparatus, including those related to the theory of catastrophes.

It is obvious for understanding and formalizing such systems new methods are required that make it possible to operate with complex arbitrarily changing structures, usually poorly structured [16]. It is the underdevelopment of the universal mathematical apparatus and management methods that explains the weak development and scope of application of network-centric structures in relation to the tourist and recreational sphere (and not only to it).

\section{About innovative strategies in the tourism and recreation sector}

And now about how to apply the modern provisions of synergy and modern management to the progressive development of TRS. It has its own specifics related to any of the economic sectors. Let us briefly analyze those problems and contradictions, that along with those already noted, hinder the innovative development of the country's tourism and recreation sector.

At present the Government of the Russian Federation is implementing a long-term state policy [17], the purpose of which is to achieve technological leadership of the Russian economy, ensure the sustainability of the country's economic growth, and increase the real incomes of citizens.

In accordance with the tourism development strategy [18] in the Russian Federation for the period up to 2035 the strategic priorities of the industry are the complexity of development and the availability of tourist services, which in turn, correspond with the national development goals to increase life expectancy, ensure sustainable growth real incomes of citizens, reducing poverty, joining the Russian Federation among the five largest economies in the world and ensuring economic growth rates higher than world ones.

For implementing the stated development directions, it is planned to develop and implement a set of measures aimed at training and retraining personnel and industry specialists.

It is obvious that the enterprises of the tourist and recreational sphere of Russia, which abounds in the world market with very attractive tourist and recreational resources cannot remain aloof from the mainstream development of the country's leading industries.

The experience of industrially developed countries that have achieved noticeable success in the development of science-intensive technologies, increasing the volume of production and export of innovative products and services allows us to highlight the following possible forms of implementation of innovation policy in the tourism and recreation sector [19]:

- "build-up" strategy - a set of long-term measures aimed at ensuring the gradual build-up of new competitive offers and services based on our own high technologies;

- "borrowing" strategy - a set of measures aimed at assimilating new technologies and services in the field of tourism and recreation, tested in developed countries, using the country's own innovative potential;

- "transfer" strategy - a set of organizational and economic measures related to the development of production of products and services of the tourism industry of new generations, which are in demand abroad through the purchase of licenses for highly efficient new technologies.

For objective reasons it is quite difficult to widely use "build-up" and "transfer" strategies of tourist and recreational technologies in Russia, in our opinion, due to limited resources, lack of investment in the tourism industry, and the unsatisfactory state of its material and technical base.

Therefore, in the short and medium terms it is advisable to focus on the implementation of the "borrowing" strategy, which can be successfully implemented through the use of mechanisms for the diffusion of innovations and advanced technologies from economically developed countries into the tourism industry of Russian regions [20].

\section{Results}

Approbation of scientific and methodological approaches to the construction of tourist and recreational systems based on the concept of network-centric control was carried out in the period from 2015 to 2019 within the framework of research work on the territory of Klinsky, Noginsky, Ramensky, Sergiev Posad municipal districts of the Moscow region, Zaraysk urban district, Likhoslavl and Spirovsky districts of the Tver region.

The problems associated with the development and functioning of municipal shopping and entertainment complexes are investigated in the context of the networkcentric concept of management. Solutions are proposed that allow taking into account all the possibilities and advantages that are inherent in the network-centric approach, namely: increasing the efficiency and effectiveness of management based on the principle of self-synchronization, which is the key in our concept.

Let us briefly consider the results obtained in the course of research work on substantiating the network- 
centric concept of managing the tourist and recreational system using the example of municipalities of two types: with a high industrial potential and an underdeveloped tourist and recreational complex (Ramenskiy municipal district of the Moscow region) and a pronounced agrarian specialization, experiencing acute demographic problems (Likhoslavl district of the Tver region).

\section{Tourist and recreational complex of the Ramensky municipal district}

The structure of the tourist and recreational complex is not optimal from the point of view of the completeness of using the tourist and recreational potential and additional opportunities associated with an increase in the tourist and excursion flow, attracting investments in the creation of tourist and supporting infrastructure, and creating additional jobs [21].

On the territory of the Ramensky municipal district (RMD) there are the most developed conditions for the formation of human resources in the field of tourism $(58 \%)$, market conditions $(56 \%)$ and the institutional environment (55\%) - Fig. 2 [21].

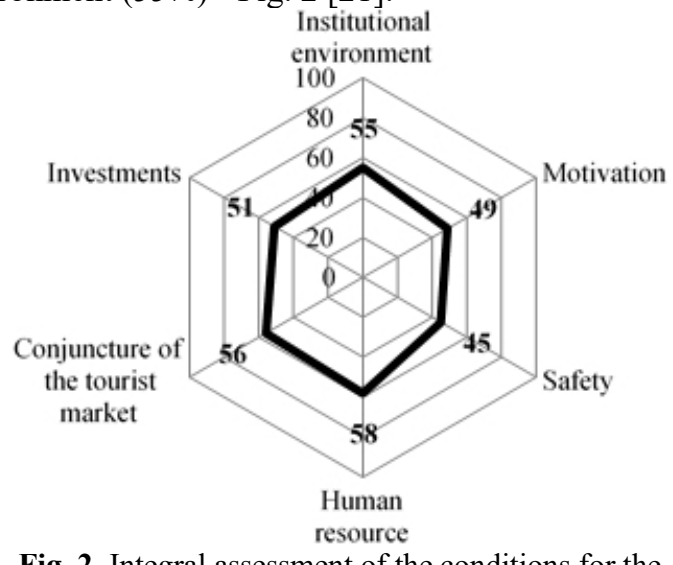

Fig. 2. Integral assessment of the conditions for the development of tourism on the RMD territory

The most pressing issues remain with regard to the choice of priorities in relation to tourism on the part of the authorities and the local population: goals and priority areas have not been determined, the tourism management system at the municipal level has not been fully formed. Tourism development initiatives are perceived by the local population rather cautiously. Nowadays the most interested group of stakeholders are entrepreneurs who see tourism as a priority area and an additional opportunity for economic growth [21].

The tourism industry of the RMD demonstrates a slight increase in the number of arrivals, but the growth rate of the tourist flow does not yet correspond to either the national or regional indicators. The possibilities of RMD in terms of cultural, educational and other types of tourism are not fully disclosed [21].

The analysis of the tourist and recreational potential of the study area showed that the species structure of the tourist and recreational resources of the RMD is quite diverse, but there are disproportions in the distribution of tourist and recreational resources and tourist infrastructure, the attractiveness of display objects for tourists remains not high enough [21].
The basis of the network-centric development strategy of the RMD tourist and recreational complex is formed by the following priorities [21]:

- $\quad$ localization of the basis for managing the value chain of a tourist product that goes beyond the boundaries of the district, including such elements as transport and logistics, system and sales market, human resources;

- development of integration mechanisms (sectoral cooperation and project management) aimed at increasing the efficiency of tourism management at the municipal level and leveling territorial disparities in the distribution of tourism and recreation resources and tourism infrastructure;

- concentration of efforts on support of existing entrepreneurs and investors, providing for the development of targeted measures to stimulate investment activity and address issues on the principle of "one window";

- differentiation of tourism products in terms of the range and cost of services for different target audiences, taking into account the species diversity of tourist and recreational resources and the development of transport infrastructure;

- priority of budget expenditures in four areas: development of tourism infrastructure, increasing tourist attractiveness, ecology, employment.

The recommended management system of the RMD tourist and recreational complex forms the basic conditions for the effective implementation of the network-centric development strategy of the RMD tourist and recreational complex: the speed of decisions made, the speed of response to ongoing changes, the personification of responsibility for the result, a high level of communication and interaction between all participants in the tourism market. Based on the technology of project management, which is the core of the network-centric concept, it is necessary to strengthen its self-organization. In 2020, several tourist enterprises, until that time interacting only with market operators, united into a pool and created their own tourist product: Gaya Severing's Ski Club, Gzhel, the Center for Technical Sports "Myachkovo" (an autodrome, a small aviation airport), health resort organizations in the village of Kratovo, Ramenskiy History and Art Museum. At present conditions are being formed on the territory of the RMD, which need to be supported on the basis of network-centric technologies, for the formation of six sub-clusters support territories of the tourist and recreational cluster "Ramenye", for: cultural and educational tourism "Ramenskoye - Kratovo - Bykovo"; health tourism "Kratovo"; industrial tourism and folk arts and crafts "Gzhel"; active tourism "Chulkovo - Myachkovo"; river tourism "Ostrovetskaya Luka"; rural tourism [21].

\section{Ethno cultural complex in the Likhoslavl region of the Tver region}

The possibilities and advantages of networking are realized in event events that take place on its territory. Among them: the festival of national cultures, the international festival-competition of architects for the 
creation of environmental installations expressing the culture of the Tver Karelian ethnic group, the international gastronomic festival "Kalitka" [22].

Such projects have several advantages and disadvantages. The advantages include strengthening the socio-cultural component of the development of rural settlements (socialization of the younger generation, motivation of local residents, the formation of a unifying principle around the cultural and historical past of the territory), increasing the recognition of the territories and promoting their tourism opportunities. The disadvantages are the discreteness of such projects (held in the high season up to three times a year) and their low economic efficiency in consolidating the results and their multiplication [22].

The main reasons for the disparities between the social and economic results of the events held include low infrastructural provision of tourist activities in rural settlements (road transport, info communication, accommodation facilities, etc.); shortcomings in the management of the tourist complex of the municipality (lack of a strategy, design solutions for tourist and recreational development, interdepartmental coordination, project groups and responsibility centers; ambiguity in the formulation of goals and objectives for the development of tourism and the formation of a tourist product of the territory and its promotion in the tourist market, weak communication between local residents and authorities) [22].

The lack of consistency in tourism management does not allow creating a solid basis for multiplying the economic results achieved in the process of implementing tourism projects. Under these conditions the solution to the identified problems is to build a network self-organizing system, the cores of which are infrastructure support facilities, social groups of local residents and elements of information and communication infrastructure. Its substantive basis is the cultural and historical heritage of the Tver Karelians, compactly living in the region for more than 400 years, and the supporting territories themselves have specialization (active tourism, national cuisine, folk art and crafts, national language and literature, Orthodoxy) [22].

On the basis of the ethno cultural complex "Myammino" a tourist and recreational attractor was created, which connected the Likhoslavl town, Myammino, Tolmachi, Kozlovo and Vydropuzhsk villages into a single excursion route "Small Karelian Ring". Nowadays active work is underway to include in the project other territories that form the ethno cultural area of life of the Tver Karelians: Maksatikhinsky, Vyshnevolotsky, Rameshkovsky, Vesyegonsky, Sonkovsky, Lesnoy districts of the Tver region. Thus, the process of the formerly spontaneous development of tourist and recreational complexes is increasingly streamlined within the network-centric system [22].

\section{Conclusions}

1. The globalization of the world order and the current conditions for the development of the Russian economy require the creation of modern tourist and recreational systems based on the network-centric approach. This makes it possible to increase their economic efficiency and significantly streamline the management process aimed at achieving these complex structures of dynamic stability in a nonlinear environment of their functioning and multivariate management decisions. The practical rely of such an important object as the attractor, which is a factor in the self-organization of the destination, is a key point.

2. Nowadays, for objective reasons in model specification of Russian TRS in the short and medium term it is advisable to focus on the implementation of the "borrowing" strategy, which can be successfully implemented through the use of innovation diffusion mechanisms and advanced information and tourismrecreational technologies.

3. The study of tourist and recreational systems at the municipal level confirmed the hypothesis about the expediency of using the network-centric concept of management to increase their efficiency and competitiveness. Using the example of various municipal tourist and recreational complexes, managed to test scientific and methodological approaches that allow:

- to fully implement the content of the network-centric control concept;

- to find a solution to the problems associated with the imbalance of strategic decisions, territorial imbalances in the distribution of tourist and recreational potential, the search and agreement of goals for the development of tourism and the construction of a management system for the tourist and recreational complex;

- to develop design solutions for achieving goals set in the context of existing resource constraints.

Being innovative the network-centric concept has a high applied value and allows solving existing problems in their interconnection, providing competitive indicators (volume of tourism, employment of supporting personnel, size of investments). The results obtained in the course of the study can be successfully replicated at the regional and state levels of tourism and recreation management, including solutions to security problems [23, 24].

\section{Acknowledgment}

The reported study was funded by RFBR according to the research projects № 18-07-00225, 18-07-00909, 1807-01111, 19-07-00455.

\section{References}

[1] Zatuliveter Yu.S. Towards global programming // Open systems. - 2003. - No. 3. - Pp. 46-47.

[2] Tanenbaum E., Van Steen M. Distributed systems. Principles and paradigms. - SPb.: Peter, 2003. - 877 p.

[3] Zatuliveter Yu.S. Problems of globalization of the control paradigm in a mathematically homogeneous field of computer information // Control problems. 2005. - No. 1. - Part I. - Pp. 1-12; - No. 2. - Part II. Pp. 13-23.

[4] Zatuliveter Y.S., Fishchenko E.A. Graph-dynamic systems with network-centric control in a mathematically homogeneous field of computer information // Management of large systems. Special Edition 30.1 "Network Models in Management". - M.: 
ICS RAS, 2010. - Pp. 567-604.

[5] Tsyshchuk E.A., Minaev V.A., Tsyshchuk G.Yu. Methodological approach to the development of a strategy for the tourist and recreational complex development of the municipal formation // Tourism and recreation: fundamental and applied research: Proceedings of the XIII International Scientific and Practical Conference. Smolensk State University, April 19-21, 2018 / under total edition of V.I. Kruzhalin. - Pp. 128-143.

[6] Buhalis D., Molinaroli E. Entrepreneurial Networks and Supply Communities in the Italian Tourism // Information Technology \& Tourism, 1 January. 2003. - Vol. 5. - No. 3. - Pp. 175-184.

[7] Buhalis D. Marketing the Competitive Destination of the Future // Tourism Management. - 2001. - No. 21 (1). - Pp. 97-116.

[8] Bedritskiy A.V. Information war: concepts and their implementation in the United States. - M.: RISS, 2008. - $187 \mathrm{p}$.

[9] Akaev A.A., Korotaev A.V., Malinetskiy G.G., Malkov S.Yu. Modeling and forecasting global, regional and national development. The second wave of the global crisis. Events of the "Arab Spring". Analysis of scenarios for the development of Russia in the coming decades. - M.: Publishing group URSS, 2012. - $488 \mathrm{p}$.

[10] Gubanov D.A., Novikov D.M., Chkhartishvili A.G. Social networks: models of information influence, management and confrontation / Ed. Corresponding Member RAS D. A. Novikov. - M.: Publishing house of physical. math. literature, 2010.- $228 \mathrm{p}$.

[11]Nicolis G., Prigogine I. Self-organization in nonequilibrium systems. - M.: Mir, 1979. - 512 p.

[12] Haken G. Synergetic. - M.: Mir, 1980. - 404 p.

[13] Burkov V.N. Fundamentals of the mathematical theory of active systems. - M.: Nauka, 1977. - 255 p.

[14] Gorodetsky A., Ilyashenko Yu. Minimal and Strange Attractors // International Journal of Bifurcation and Chaos. - 1996. - Vol. 6. - No. 6. - Pp. 1177-1183.

[15]Zolotarev O.V. Methods and tools for modeling the domain. To the collection works based on the materials of the conference "Civilization of Knowledge: Problems of Social Communications". M.: RosNOU, 2012. - Pp. 71-72.

[16] Avdeeva Z.K., Kovriga S.V., Makarenko D.I. Cognitive modeling for solving problems of control of semi-structured systems (situations) // Management of large systems. - 2007. - No. 16. - Pp. 26-39.

[17] Decree of the President of the Russian Federation of May 7, 2018 No. 204 "On national goals and strategic objectives of the development of the Russian Federation for the period up to 2024".

[18] The strategy for the development of tourism in the Russian Federation for the period up to 2035, approved by the order of the Government of the Russian Federation of September 20, 2019 No. 2129r.

[19]Zernov V.A., Minaev V.A. Innovative training and business processes in international network systems // Higher education today. 2013. No. 6. - Pp. 9-16.

[20]Zolotareva V.P., Zolotarev O.V., Yashkova N.V.
Project management. Teaching aid // Stimul-ST LLC. - Nizhny Novgorod, 2016.

[21]R\&D report "Concept for the development of the tourist and recreational complex of the Ramensky municipal district" (reg. No. AAAA-A19119121890096-7, 2016. - 407 p.).

[22]R\&D report "Development of the concept of an investment project for the construction of an ethno cultural complex in the Likhoslavl district of the Tver region" (reg. No. AAAA-A17-117060610041-7, 2017. - 78 p.).

[23] Minaev V. A., Faddeev A. O. Safety and recreation: systemic view on the problem of risks / Proceedings of the II International scientific and practical conference "Tourism and recreation: fundamental and applied research". April 20, 2007. Moscow, Lomonosov Moscow state University. - Pp. 329-334.

[24] Minaev V. A., Faddeev A. O. Methods of geoecological risk and safety assessment of landscapeterritorial complexes / Proceedings of the Seventeenth scientific and technical conference "Security systems" - SS-2008, October 30, 2008. Moscow, Academy of the State fire service of the Russia EMERCOM. - Pp. 96-102.

\section{About the authors}

Vladimir A. Minaev, Doctor of Engineering Sciences, Full Professor, Professor of Bauman Moscow State Technical University. E-mail: m1va@yandex.ru.

Evgeniy A. Tsyshchuk, Candidate of Pedagogy, Senior Researcher at ANO "Scientific and Research Center for Information in Physics and Technique". E-mail: evgenytsyshchuk@gmail.com

Galina Yu. Tsyshchuk, Deputy Dean of the Business School of Synergy University. E-mail: gtsyshchuk@list.ru 